\title{
Placental growth factor may predict increased left ventricular mass index in patients with mild to moderate chronic kidney disease - a prospective observational study
}

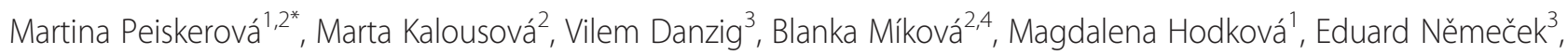
Amjad Bani-Hani ${ }^{3}$, David Ambrož ${ }^{3}$, Hana Benáková2, Ales Linhart ${ }^{3}$, Tomas Zima $^{2}$ and Vladimir Tesař ${ }^{1}$

\begin{abstract}
Background: Placental growth factor [PIGF) is a cardiovascular (CV) risk marker, which is related to left ventricle hypertrophy $(\mathrm{LVH})$ in animal models. Currently there are no data available regarding the possible relationship of PIGF and the development of LVH or diastolic dysfunction in patients with chronic kidney disease (CKD) and the relationship of PIGF to other $\mathrm{CV}$ risk factors in CKD patients. The aim of our study was to determine the possible association of PIGF and several other CV risk markers to echocardiographic parameters in CKD population.

Methods: We prospectively examined selected laboratory (PIGF, fibroblast growth factor-23 -FGF23, vitamin D, parathyroid hormone, extracellular newly identified RAGE-binding protein - EN-RAGE, B-type natriuretic peptide BNP) and echocardiographic parameters in 62 patients with CKD 2-4. Mean follow-up was $36 \pm 10$ months. Laboratory and echocardiographic data were collected 2-3 times, at the shortest interval of 12 months apart. Multivariate regression analysis was used to detect independent correlations of variables.

Results: Increased left ventricular mass index (LVMI, g/m 2.7 ) was found in 29\% patients with CKD 2-4, left ventricular (LV) diastolic dysfunction was detected in $74.1 \%$ patients (impaired LV relaxation in $43.5 \%$ patients and pseudonormal pattern in 30.6\% patients). After $36 \pm 10$ months increased LVMI was found in $37.1 \%$ patients with CKD 2-4, LV diastolic dysfunction was detected in $75.8 \%$ patients (impaired LV relaxation in $43.5 \%$ patients and pseudonormal pattern in 32.3\% patients). Following independent correlations were found: LVMI was related to PIGF, cholesterol, BNP, systolic blood pressure and serum creatinine. EN-RAGE correlated positively with left atrial diameter and inversely with E/A ratio. During the follow-up we found a significant increase in LVMI and left atrial diameter, whereas a significant decrease in LVEF was noted.
\end{abstract}

Conclusion: According to our data, PIGF is independently related to increased LV mass in CKD, whereas EN-RAGE is more likely related to diastolic dysfunction in this population.

Keywords: Cardiovascular disease, Chronic kidney disease, Echocardiography, Extracellular newly identified RAGEbinding protein (EN-RAGE), Left ventricular mass index, Left ventricular hypertrophy, Left ventricular diastolic function, Placental growth factor (PIGF)

\footnotetext{
* Correspondence: mpeiskerova@seznam.cz

'Department of Nephrology, First Faculty of Medicine, Charles University, Prague, Czech Republic

${ }^{2}$ Institute of Medical Biochemistry and Laboratory Medicine, First Faculty of Medicine, Charles University and General University Hospital, Prague, Czech Republic

Full list of author information is available at the end of the article
} 


\section{Background}

Cardiovascular risk in patients with chronic kidney disease is increased in early stages of renal insufficiency and rises with its progression. Traditional as well as specific CKDrelated risk factors lead to vascular calcification, left ventricular hypertrophy (LVH) and myocardial fibrosis [1-3]. In CKD patients, LVH is a common condition originating in early CKD stages and its prevalence progresses with declining renal function [4]. LVH may develop as a compensatory mechanism to volume and pressure overload, but finally it contributes to the unfavourable outcome. LVH in CKD is typically accompanied by collagen accumulation, arteriolar wall thickening, calcification, and capillary rarefaction, reduction in the number of cardiomyocytes and hypertrophy. These mechanisms accelerate the onset of systolic and diastolic dysfunction of the left ventricle. Left ventricular (LV) diastolic dysfunction is an abnormality of relaxation, filling or distensibility of the left ventricle that portends a poor prognosis regardless of any associated systolic dysfunction [5]. Three types of LV diastolic dysfunction involve: 1. impaired relaxation (grade I) 2. pseudonormalization (grade II) and 3.restrictive filling (grade III).

A number of pathways possibly responsible for the high CV risk in CKD are currently being studied. These mechanisms include hypertension, hyperactivity of the renin-angiotensin-aldosterone system, anaemia, sodium and volume retention, endothelial dysfunction, mineral and vitamin $\mathrm{D}$ disorders, micro-inflammation and oxidative stress [3]. These pathways are under constant research, including investigation of biomarkers possibly linking CKD to CV pathology, such as placental growth factor (PlGF), extracellular newly identified RAGEbinding protein (EN-RAGE), metalloproteinases, fibroblast growth factor 23 (FGF23), 25OHvitaminD and parathyroid hormone $(\mathrm{PTH})$.

One of the above mentioned biomarkers - Placental growth factor (PlGF) - is a 149 aminoacid heterodimer, expressed in human placenta, heart, thyroid gland, lung and skeletal muscle. PlGF is a member of the proproliferative vascular endothelial growth factor family and a pro-atherogenic cytokine which stimulates angiogenesis in ischemic tissues. It is up-regulated in atherosclerotic lesions, stimulates vascular smooth muscle growth and up-regulates production of tumour necrosis factor (TNF). PIGF is a biomarker of vascular inflammation and CV risk [6]. In animal models, PIGF is related to LV hypertrophy $[7,8]$, however little is known about the relation of PlGF to $\mathrm{LVH}$ in human population. Another pro-atherogenic molecule, Pregnancy associated protein (PAPP-A), belongs to the family of metalloproteinases (MMPs). It has been found in plasma, vascular smooth muscle cells and in atherosclerotic plaques. High plasma levels of PAPP-A have been found in dialysis patients [9]. Products of non-enzymatic glycation and oxidation of proteins and lipids, advanced glycation-end products (AGEs), accumulate in CKD and they play a role in the development of atherosclerosis. Binding of AGEs to their receptor (RAGE) activates the pro-inflammatory transcription factor NF-kB. EN-RAGE is an extracellular ligand for RAGE which has been found to exert proinflammatory effects [10]. Impaired calcium-phosphate metabolism is another factor contributing to the high CV morbidity and mortality in CKD [11] and vitamin D deficiency resulting in increased plasma FGF23 levels in CKD patients might directly cause vascular calcification, increased arterial stiffness, endothelial dysfunction and LV hypertrophy [12].

No data exist so far, about the possible relationship of PIGF and the development of LVH or diastolic dysfunction in CKD patients and the possible relationship of PlGF and other CV risk markers. Little is known about echocardiographic changes in patients with earlier CKD stages. Therefore, we aimed to study the possible association of PIGF and several other pro-atherogenic molecules or CV risk markers with echocardiographic parameters in CKD 2-4 patients.

\section{Methods}

Between December 2004 and May 2009, 76 subjects with mild to moderate renal insufficiency (CKD 2-4) were consecutively recruited in the Outpatient unit of the Department of Nephrology (General University Hospital, Charles University, Prague). These subjects were followed during a mean period of $36 \pm 10$ months. We prospectively examined selected laboratory and echocardiographic characteristics of these subjects. Data were collected 2-3 times, at the shortest interval of 12 months apart. During the follow up period 8 patients died and 6 withdrew the informed consent. Final data analysis was performed only in 62 patients who completed the whole follow up period. Estimated glomerular filtration rate (eGFR) was calculated by MDRD formula. CKD was defined as a reduction in eGFR below $1 \mathrm{ml} / \mathrm{s}$ / $1.73 \mathrm{~m}^{2}$.

Clinical and demographic characteristics of the group are presented in Table 1. Etiology of CKD was: ischemic nephropathy (21\%), IgA nephritis (15\%), chronic pyelonephritis (13\%), hypertensive nephropathy (11\%), diabetic nephropathy (10\%), ANCA associated vasculitis (5\%), lupus nephritis (5\%), and other (20\%). About 92\% of patients received ACE inhibitors and/or AR blockers, 13\% were substituted with calcium, $44 \%$ received calcitriol and $61 \%$ were on statin therapy.

History of $C V$ disease was taken from medical records of each patient, comprising coronary heart disease, peripheral arterial obstructive disease and/or cerebrovascular disease. History of CV disease was noted in 31 patients $(50 \%)$. No patient had symptoms of severe heart 
Table 1 Baseline clinical and demographic characteristics of the study group

\begin{tabular}{ll}
\hline Variable \pm SD & 62 \\
\hline Number of patients & $62 \pm 15$ \\
Age (years) & 37 \\
Men & 25 \\
Women & $26,9 \pm 3,9$ \\
BMI (kg/m ${ }^{2}$ ) & 88,7 \\
Hypertension \% & $133 \pm 16$ \\
Mean systolic BP (mm Hg) & $80 \pm 7$ \\
Mean diastolic BP (mm Hg) & $3 \pm 2$ \\
Number of antihypertensive drugs & 50 \\
History of CVD \% & 21 \\
DM \% & \\
\hline
\end{tabular}

Abbreviations: $B M I$ Body mass index, $B P$ blood pressure, $C V D$ cardiovascular disease, DM Diabetes mellitus.

failure (NYHA III. or IV.) or hemodynamically significant valvular defect.

\section{Blood samples}

Fasting venous blood samples from each patient were collected. All samples were centrifuged for $10 \mathrm{~min}$ at $1.450 \mathrm{~g}\left(4^{\circ} \mathrm{C}\right)$. Sera were stored at $-80^{\circ} \mathrm{C}$ until analysis.

\section{Biochemical analysis}

FGF23 (C terminal fragment) was measured with ELISA kit according to the manufacturer protocol (Immune topics, San Clements, CA, USA). PAPP-A was assessed immunochemically with the TRACE (Time Resolved Amplified Cryptate Emission) technology based on nonradiating energy transfer (commercial kit KRYPTORPAPP-A, Brahms, Germany). MMP-2 and PlGF were measured with ELISA, Standard kits Quantikine, RD systems, Minneapolis, MN, USA. Biointact parathyroid hormone levels were analysed with ECLIA method (ROCHE, analyser MODULAR SWA). Brain natriuretic peptide (BNP) and troponin I (cTnI) were measured by chemiluminiscence methods (UniCel DxC 880i - Beckman Coulter analyzer). sRAGE and EN-RAGE were measured using standard ELISA kits according to the manufacturers' protocols: sRAGE (Quantikine, RD Systems, Minneapolis, MN, USA, www.rndsystems.com), EN-RAGE (CirculexTM, CycLex Co. Ltd., Nagano, Japan, www.cyclex.xo.jp). Routine biochemical parameters were assessed by standard laboratory methods.

Echocardiography was carried out approximately 2 hours after blood sampling.

Complete two-dimensional M-mode and Doppler studies were performed via standard approaches, using
Vivid 7 (GE Medical system, Waukesha, Winconsin). Mmode examination was performed according to American Society of Echocardiography guidelines [13] LV mass was determined using standard formula, as follows: Left ventricular mass $=0.8 \times(1.04 \times($ LVEDD + PWTd + SWTd $\left.)^{3}-(\text { LVEDD })^{3}\right)+0.6$ [13]. The values were indexed by the patient's height ${ }^{2.7}$, thus obtaining left ventricular mass index (LVMI). LV hypertrophy was defined as LV mass index $>46.7 \mathrm{~g} / \mathrm{m}^{2.7}$ in women or $49.2 \mathrm{~g} / \mathrm{m}^{2.7}$ in men. Relative wall thickness, calculated as 2-times posterior wall thickness divided by LV internal diastolic dimension, was used to characterise LV geometry into following categories: normal ( $\leq 0.42$ and normal LVM), concentric remodeling (normal LVMI but RWT $>0.42$ ), concentric hypertrophy (- increased LVMI and RWT $>0.42$ ), and eccentric hypertrophy (- increased LVMI and RWT $\leq 0.42$ ). LV volumes, comprising end-diastolic (LVEDV) and endsystolic volume (LVESV) were estimated using modified Simpson method, and used to calculate LV ejection fraction. Doppler characteristics of LV filling and diastolic function were assessed by using transmitral flow pattern along with pulmonary venous inflow parameters. In most patients we recorded mitral annular velocities. According to the current recommendations the filling was categorized as normal, impaired relaxation, pseudonormal and restrictive $[14,15]$. Left atrial diameter (LAD) was indexed to body surface area, obtaining the parameter LAD/BSA $\left(\mathrm{mm} / \mathrm{m}^{2}\right)$. In patients with mild diastolic dysfunction, the mitral E/A ratio is $<0.8$, deceleration time of inflow of the E wave, (DT) is $>200 \mathrm{~ms}$. In patients with moderate diastolic dysfunction (grade II), the mitral E/A ratio is 0.8 to 1.5 (pseudonormal) and decreases by $\geq 50 \%$ during the Valsalva maneuver. With severe diastolic dysfunction (grade III), restrictive LV filling occurs with an E/A ratio $\geq 2$, DT $<160 \mathrm{~ms}[14,15]$.

The study was approved by the Ethical Committee of General University Hospital in Prague, reference number: 50/08. A written informed consent was obtained from all participants.

\section{Statistics}

The results of biochemical parameters are expressed as mean $\pm \mathrm{SD}$, in case of non-normal data distribution as medians and interquartile ranges. Comparisons were conducted with paired sample $\mathrm{t}$ tests for normally distributed continuous variables and Wilcoxon test for non-normal distributions. Variables with non-normal distributions were $\ln$ - transformed where appropriate. Association among analyzed parameters was assessed by Pearson's correlation coefficient. Subsequently, linear regression analysis for determinants of echocardiographic parameters influential variables was performed. All variables significantly associated with echocardiographic characteristics were included in the multiple regression 
stepwise analyses (serum albumin, PlGF, serum cholesterol, $25 \mathrm{OH}$ vitamin D, BNP, FGF23, serum creatinine, ENRAGE, PTH, PAPP, Pi, sRAGE, serum TAG, MMP2). Qualitative variables, such as tobacco smoking, history of CV disease, use of ACE inhibitors, were analysed using the Kruskal-Wallis test. Chi-Squared Test for Trend was used to compare baseline and final echocardiographic findings in the subject group (Table 2). Results were considered as statistically significant at $\mathrm{p}<0.05$. All analyses were performed using MedCalc 9.3 (MedCalc Software Comp. Mariakerke, Belgium).

Table 2 Echocardiographic characteristics (\%) of the study group $(n=62)$

\begin{tabular}{|c|c|c|c|}
\hline & Baseline & $\begin{array}{c}\text { After } 36 \\
\text { months }+-10\end{array}$ & $\begin{array}{l}\mathrm{p} \text { value chi square } \\
\text { test for trend }\end{array}$ \\
\hline \multicolumn{4}{|c|}{ LV mass index $\left(\mathrm{g} / \mathrm{m}^{2.7}\right)$} \\
\hline normal & 71,0 & 62,9 & $p=0.22 \mathrm{NS}$ \\
\hline increased & 29,0 & 37,1 & \\
\hline \multicolumn{4}{|c|}{ LV geometry } \\
\hline $\begin{array}{l}\text { normal LV } \\
\text { geometry }\end{array}$ & 56,5 & 43,5 & $p=0.25 \mathrm{NS}$ \\
\hline $\begin{array}{l}\text { concentric } \\
\text { remodelation }\end{array}$ & 12,9 & 21,0 & \\
\hline $\begin{array}{l}\text { concentric } \\
\text { hypertrophy }\end{array}$ & 9,7 & 9,7 & \\
\hline $\begin{array}{l}\text { excentric } \\
\text { hypertrophy }\end{array}$ & 21,0 & 25,8 & \\
\hline \multicolumn{4}{|c|}{ LVEF (\%) } \\
\hline normal & 88,7 & 87,1 & $p=0.68 \mathrm{NS}$ \\
\hline decreased & 11,3 & 12,9 & \\
\hline \multicolumn{4}{|c|}{$\operatorname{LAD}\left(\mathrm{cm} / \mathrm{m}^{2}\right)$} \\
\hline normal & 98,4 & 98,4 & $p=1.00 \mathrm{NS}$ \\
\hline increased & 1,6 & 1,6 & \\
\hline \multicolumn{4}{|c|}{ LV diastolic function } \\
\hline $\begin{array}{l}\text { normal LV } \\
\text { diastolic function }\end{array}$ & 25,8 & 24,2 & $p=0.96 \mathrm{NS}$ \\
\hline impaired relaxation & 43,5 & 43,5 & \\
\hline $\begin{array}{l}\text { pseudonormal } \\
\text { pattern }\end{array}$ & 30,6 & 32,3 & \\
\hline \multicolumn{4}{|c|}{ E/A ratio } \\
\hline below 0.8 & 46,8 & 48,4 & $p=0,06$ NS \\
\hline $0-8-1.5$ & 50,0 & 40,3 & \\
\hline above 2 & 3,2 & 11,3 & \\
\hline \multicolumn{4}{|c|}{ DTE-MI (ms) } \\
\hline above 200 & 38,7 & 62,9 & $p<0.01$ \\
\hline $160-200$ & 37,1 & 27,4 & \\
\hline under 160 & 24,2 & 9,7 & \\
\hline
\end{tabular}

Abbreviations: E/A ratio Ratio between early $(\mathrm{E})$ and late (atrial - A) ventricular filling velocit, DTE-MI Decelaration Time on Mitral Valve, $L A D$ left atrial diameter, $L V$ left ventricular.

\section{Results}

1. Baseline echocardiographic parameters of the study group (Table 2).

Increased LV mass was noted in $29 \%$ patients. We identified $56.5 \%$ subjects with normal LV geometry, $12.9 \%$ subjects with concentric remodelling, $9.7 \%$ subjects with concentric hypertrophy and $21 \%$ subjects with eccentric hypertrophy. Normal LV diastolic function was found in $25.8 \%$ patients, impaired LV relaxation in $43.5 \%$ patients and pseudonormal pattern in $30.6 \%$ patients. No one met the criteria of restrictive pattern of $\mathrm{LV}$ diastolic filling.

2. Echocardiographic parameters of the study group after $36 \pm 10$ months (Table 2).

Increased LV mass was noted in $37.1 \%$ patients. We identified $43.5 \%$ subjects with normal LV geometry, $21 \%$ subjects with concentric remodelling, 9.7\% subjects with concentric hypertrophy and $25.6 \%$ subjects with eccentric hypertrophy. Normal LV diastolic function was found in $24.2 \%$ patients, impaired LV relaxation in $43.5 \%$ patients and pseudonormal pattern in $32.3 \%$ patients. No one met the criteria of restrictive pattern of LV diastolic filling.

3. Independent correlations of echocardiographic parameters, laboratory markers and blood pressure (Table 3, Figure 1).

LV mass index was positively related to PlGF, BNP, systolic BP and serum creatinine. BNP positively correlated also with left atrial diameter. EN-RAGE was positively related to left atrial diameter and inversely to E/A. PTH inversely correlated with LVEF. No independent correlations were found between echocardiographic parameters and haemoglobin, PAPP-A, FGF23 or vitamin D levels. PlGF was not related to blood pressure.

4. Impact of renal function on laboratory and echocardiographic parameters and their changes during the follow-up period (multiple regression) (Table 4, Figure 2). eGFR was positively related to $\mathrm{E} / \mathrm{A}$ ratio and inversely related to LVMI and left atrial diameter. During the follow-up, with the decline of eGFR, we noted a significant increase in LVMI, left atrial diameter, EN-RAGE, FGF23 and BNP, whereas a decrease was observed in LVEF, serum albumin, vitamin D and haemoglobin. No significant changes in blood pressure were noted.

5. Laboratory parameters in patients with history of CV disease.

History of $\mathrm{CV}$ disease was noted in $50 \%$ of patients. These patients had higher LVMI $(\mathrm{p}<0.02)$, serum 
Table 3 Independent correlations of laboratory and echocardiographic parameters (stepwise multiple regression)

\begin{tabular}{|c|c|c|c|c|c|c|c|c|c|c|c|}
\hline & LVMI1 & LVMI3 & LAD 1 & LAD 2 & LAD 3 & EF1 & EF2 & EF3 & E/A 1 & E/A 2 & E/A 3 \\
\hline \multirow[t]{2}{*}{ MDRD } & $r=-0,31$ & $r=-0,37$ & $r=-0,25$ & $r=-0,37$ & $r=-0,41$ & - & - & - & $r=0,54$ & $r=0,43$ & $r=0,40$ \\
\hline & $p=0,02$ & $p<0,01$ & $p=0,06$ & $p<0,02$ & $p<0,01$ & & & & $p<0,0001$ & $p<0,01$ & $p<0,01$ \\
\hline \multirow[t]{2}{*}{ Serum Albumine } & $r=-0,27$ & - & - & $r=-0,33$ & $r=-0,33$ & - & - & - & & - & - \\
\hline & $p<0,05$ & & & $p<0,05$ & $p=0,02$ & & & & & & \\
\hline \multirow[t]{2}{*}{ PTH } & - & - & - & - & - & - & $r=-0,47$ & - & - & - & - \\
\hline & & & & & & & $p<0,01$ & & & & \\
\hline \multirow[t]{2}{*}{ EN-RAGE } & - & - & $r=0,35$ & - & - & $r=-0,26$ & - & - & $r=-0,34$ & - & - \\
\hline & & & $p<0,01$ & & & $p<0,05$ & & & $p=0,01$ & & \\
\hline \multirow[t]{2}{*}{ PIGF } & - & $r=0,31$ & - & - & $r=0,36$ & - & - & - & - & - & - \\
\hline & - & $p<0,02$ & & & $p<0,01$ & & & & & & \\
\hline \multirow[t]{2}{*}{ BNP } & $r=0,42$ & $r=0,51$ & $r=0,27$ & $r=0,30$ & $r=0,50$ & - & - & - & - & - & - \\
\hline & $p<0,01$ & $p<0,001$ & $p<0,05$ & $p=0,08$ & $p<0,01$ & & & & & & \\
\hline \multirow[t]{2}{*}{ systolic BP } & - & $r=0,31$ & - & - & - & - & - & - & - & - & - \\
\hline & & $p<0,02$ & & & & & & & & & \\
\hline
\end{tabular}

Legend: The 3 values for each parameter stand for serial echo exams at different time points (1: baseline assessment, 2: control 1 assessment 3: control 2 assessment). Only significant correlations are presented, independent correlations are highlighted.

Abbreviations: BNP brain natriuretic peptide, BP blood pressure, E/A Ratio between early (E) and late (atrial - A) ventricular filling velocity, EF left ventricular ejection fraction, EN-RAGE Extracellular newly identified RAGE-binding protein, DT deceleration time on mitral valve, LAD left atrial diameter, LVMI left ventricle mass index, MDRD modification of diet in renal disease, PIGF placental growth factor, PTH parathyroid hormone, $r$ Pearson correlation coefficient.

creatinine $(\mathrm{p}<0.01)$, triacyglycerols $(\mathrm{p}<0.05)$, FGF23 $(\mathrm{p}<0.02)$ and PAPP-A $(\mathrm{p}<0.05)$, whereas they had lower 25OHvitamin D $(\mathrm{p}<0.05)$ and serum albumin levels ( $p<0.01)$, compared to those free of such history. Relation of PlGF to $\mathrm{CV}$ disease history was of borderline significance $(\mathrm{p}=0.05)$.

To sum up the results: During the follow-up period (initially, resp. after $36 \pm 10$ months) we noted an increased LVMI in 29\%, resp. $37.1 \%$ of patients, abnormal LV geometry in $43.5 \%$, resp. $56.5 \%$ and abnormal LV diastolic function in $74.1 \%$, resp. 75.8 of subjects. However, these trends were not significant. LVMI correlated with PlGF, BNP, systolic $\mathrm{BP}$ and eGFR. LV diastolic function was related to

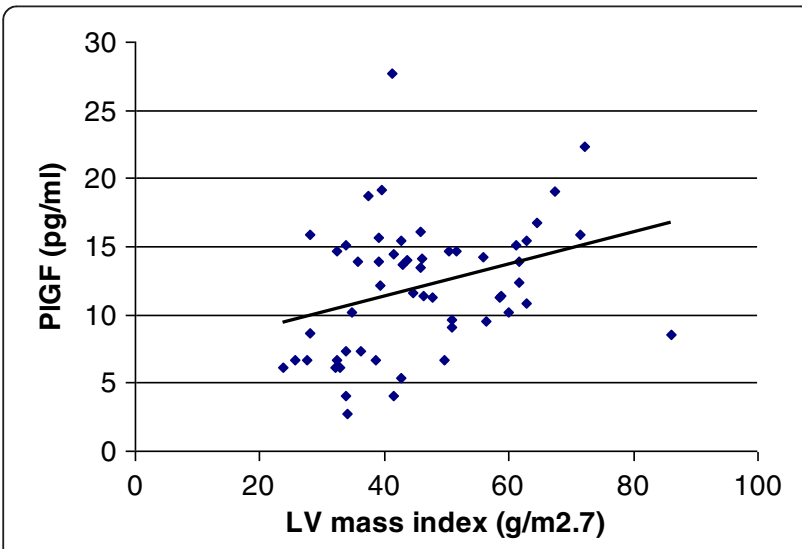

Figure 1 Correlation of PIGF levels to LV mass index $\left(\mathrm{g} / \mathrm{m}^{2.7}\right)$ $\mathbf{r}=\mathbf{0 . 3 1}, \mathbf{p}<\mathbf{0 . 0 2}$. Based on final data. PIGF: placental growth factor, LV: left ventricle.
EN-RAGE and eGFR. During the follow-up, with declining eGFR we noted an increase in LVMI, left atrial diameter, EN-RAGE, FGF23 and BNP, whereas a decrease was observed in LVEF, serum albumin, vitamin D and haemoglobin.

\section{Discussion}

In the group of patients with mild to moderate CKD, we noted a high prevalence of LV remodelling and increased LV mass with rising frequency in more severe CKD. We detected increased LVMI in 14\% patients with CKD 2, in $21 \%$ with CKD 3 and in $48 \%$ patients in CKD 4 stages (Figure 2, Table 2). Levin et al. have reported the prevalence of $\mathrm{LVH}$ in $26.7 \%$ of patients with GFR $>50 \mathrm{~mL} / \mathrm{min}$, in $30.8 \%$ of those with GFR between 25 and $49 \mathrm{~mL} / \mathrm{min}$ and in $45.2 \%$ of patients with severe CKD (GFR $<25 \mathrm{~mL} / \mathrm{min}$ [16], which is more or less in accordance with our findings. High prevalence of increased LVMI in CKD has been repeatedly described [16-18], but the studies are difficult to compare due to different definitions of LVH, different study populations and variations in blood pressure control, including the use of ACE inhibitors and/or ARBs.

LV mass index in our study correlated independently with systolic BP, BNP, serum creatinine and PlGF. The relationship of BNP to LVMI and $\mathrm{CV}$ pathology has already been described [19-21] and a correlation of LVMI to BNP, CRP and troponin $\mathrm{T}$ has been reported in CKD 3-4 stages [22]. However, in our present study we failed to show a significant correlation of LVMI to troponin or CRP. 
Table 4 Changes of laboratory and echocardiographic parameters during the follow-up period

\begin{tabular}{|c|c|c|c|c|c|c|}
\hline Parameter & Baseline & $\begin{array}{c}\text { After } \\
18 \text { months } \pm 5\end{array}$ & $\begin{array}{c}\text { After } \\
36 \text { months } \pm 10\end{array}$ & $\begin{array}{l}p \text { value for } \\
\text { Baseline vs. } \\
18 \text { months } \\
\text { assessment }\end{array}$ & $\begin{array}{c}p \text { value for } \\
18 \text { months } \\
\text { assessment vs. } \\
36 \text { months assessment }\end{array}$ & $\begin{array}{l}p \text { value for } \\
\text { Baseline } \\
\text { vs. } 36 \\
\text { assessment }\end{array}$ \\
\hline \multirow[t]{2}{*}{ eGFR (MDRD) (ml/s) } & 0.6 & 0.57 & 0.49 & $p<0.01$ & $p<0.05$ & $p<0.01$ \\
\hline & $(0.25-1.6)$ & $(0.25-1.3)$ & $(0.26-2.8)$ & & & \\
\hline Haemoglobin $(g / l)$ & $128.5 \pm 20.0$ & $128.8 \pm 20.7$ & $124.3 \pm 18.8$ & $p<0.01$ & $p<0.01$ & NS \\
\hline \multirow[t]{2}{*}{ Serum Phosphate (mmol/l) } & 1.10 & 1.16 & 1.20 & NS & NS & NS \\
\hline & $(1.00-1.29)$ & $(1.00-1.45)$ & $(1.00-1.36)$ & & & \\
\hline \multirow[t]{2}{*}{ Parathyroid hormone (pg/ml) } & 5.96 & 6.34 & 7.52 & NS & NS & NS \\
\hline & $(3.56-9.22)$ & $(4.56-11.98)$ & $(3.63-15.59)$ & & & \\
\hline $250 H$ Vitamin D (ng/ml) & $23.47 \pm 8.91$ & $25.04 \pm 9.61$ & $20.87 \pm 7.79$ & NS & $p<0.01$ & $p<0.02$ \\
\hline \multirow[t]{2}{*}{ FGF23 (RU/ml) } & 89.6 & 100.1 & 127.0 & $p<0.01$ & $p<0.05$ & $p<0.0001$ \\
\hline & $(64.8-167.1)$ & $(73.0-228.8)$ & $(78.3-282.4)$ & & & \\
\hline \multirow[t]{2}{*}{ PAPP-A (mIU/l) } & 8.3 & 8.7 & 9.3 & NS & NS & NS \\
\hline & $(7.0-10.2)$ & $(7.6-10.5)$ & $(7.5-12.6)$ & & & \\
\hline \multirow[t]{2}{*}{ sRAGE (pg/ml) } & 976.3 & 919.1 & 1040.7 & NS & NS & NS \\
\hline & $(720.6-1495.2)$ & $(643.9-1336.3)$ & $(719.1-1375.1)$ & & & \\
\hline \multirow[t]{2}{*}{ EN-RAGE (ng/ml) } & 160.5 & 255.2 & 269.8 & $p<0.05$ & NS & $p<0.001$ \\
\hline & $(100.5-240.3)$ & $(164.6-297.0)$ & $(163.0-326.3)$ & & & \\
\hline \multirow[t]{2}{*}{ PIGF (pg/ml) } & 10.80 & 11.05 & 12.5 & $p<0.02$ & NS & NS \\
\hline & $(7.8-14.2)$ & $(8.5-15.6)$ & $(8.5-14.7)$ & & & \\
\hline MMP-2 (ng/ml) & $214.5 \pm 50.6$ & $206.5 \pm 39.2$ & $221.9 \pm 61.6$ & NS & NS & NS \\
\hline \multirow[t]{2}{*}{ Troponin I (ng/ml) } & 0.01 & 0.01 & 0.01 & NS & NS & NS \\
\hline & $(0.01-0.01)$ & $(0.01-0.01)$ & $(0.01-0.01)$ & & & \\
\hline \multirow[t]{2}{*}{ BNP (pg/ml) } & 30.0 & 57.0 & 77.0 & $p<0.01$ & NS & $p<0.0001$ \\
\hline & $(15.0-91.0)$ & $(27.8-107.3)$ & $(40.0-195.0)$ & & & \\
\hline Left ventricle mass index $\left(\mathrm{g} / \mathrm{m}^{2.7}\right)$ & $43.6 \pm 14.6$ & $45.3 \pm 16.0$ & $45.7 \pm 13.4$ & NS & NS & $p<0.05$ \\
\hline Left ventricle EF (\%) & $64.7 \pm 7.8$ & $64.5 \pm 5.8$ & $62.7 \pm 8.0$ & $p<0.05$ & NS & $p<0.05$ \\
\hline Left atrial diameter $\left(\mathrm{cm} / \mathrm{m}^{2}\right)$ & $2.14 \pm 0.64$ & $2.05 \pm 0.55$ & $2.19 \pm 0.50$ & NS & NS & $p<0.01$ \\
\hline \multirow[t]{2}{*}{ E/A ratio } & 0.83 & 0.83 & 0.81 & NS & NS & NS \\
\hline & $(0.67-1.14)$ & $(0.69-0.98)$ & $(0.72-1.04)$ & & & \\
\hline
\end{tabular}

Arithmetic mean \pm SD or median (Interquartile Range).

Comparison: Paired samples $t$-test for normal distributions, resp. Wilcoxon test for skewed distrubutions.

Abbreviations: BNP brain natriuretic peptide, BSA body surface area, E/A ratio Ratio between early (E) and late (atrial - A) ventricular filling velocity eGFR: estimated glomerular filtration rate, EN-RAGE Extracellular newly identified RAGE-binding protein, FGF23 fibroblast growth factor 23, MDRD modification of diet in renal disease, MMP-2 matrix-metaloproteinase 2, PAPP-A pregnancy associated protein A, PIGF placental growth factor.

In contrast, the correlation of PlGF to LV mass in CKD patients has not been reported so far. In an animal study [23], PIGF overexpressing mice exhibited a greater cardiac hypertrophic response, an increase in capillary density and in fibroblast content in the heart in response to stress. Thus, PIGF overexpressing mice showed a type of cardiac growth, which was protective against signs of failure. Contrarily, PlGF(-/-) mice died of heart failure within 1 week of pressure overload. PIGF probably works through endothelial cells and fibroblasts, secondarily stimulating the myocytes through paracrine factors, such as interleukin-6 [24]. PlGF has been reported to stimulate angiogenesis in the infarction border [7], to promote atherosclerotic intimal thickening and macrophage accumulation and has been associated with long-term prediction of $\mathrm{CHD}[25,26]$. In human atherosclerotic lesions PIGF expression has been associated with plaque inflammation, suggesting its role in plaque destabilization. Delivery of anti-PIGF antibody delayed the progression of atherosclerotic plaques to vulnerable lesions [24]. The expression of PlGF in human vascular endothelial and smooth muscle cells has been reported to be induced by angiotensin II and aldosterone [8] and conversely, mineralocorticoid antagonists have been shown to inhibit PlGF 


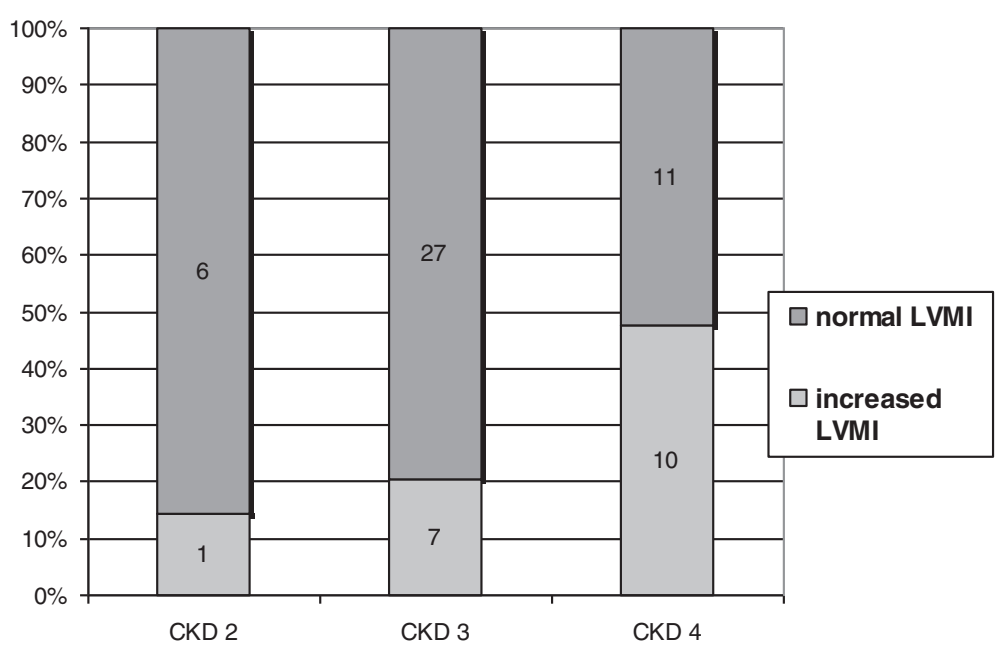

Figure 2 LV mass index $\left(\mathbf{g} / \mathbf{m}^{2.7}\right)$ in different CKD stages. Based on baseline data. LV: left ventricle, CKD: chronic kidney disease.

expression in human vessels [27]. PIGF levels have been reported to be significantly higher in CKD 1-4 stage and hemodialysis patients compared to controls [28]. Increased PIGF levels have been found in patients with CV event history compared to those free of such history [28] which is in accordance with our findings.

$\mathrm{LV}$ hypertrophy is a strong predictor of $\mathrm{CV}$ events and of the risk of progression to dialysis [18]. Interestingly, several studies in CKD patients have shown the lack of correlation between blood pressure and LV mass [29], suggesting that other neuro-humoral factors, promoting myocardial fibrosis, might play a key role in the increase of LV mass. In CKD patients, LV mass has been reported to be independently related e.g. to albuminuria, FGF23 [29-31] and to CaxPO4 [32]. In a prospective study in 3879 CKD subjects, higher FGF23 levels were associated to mortality risk [12]. FGF23 caused hypertrophy of isolated rat cardiomyocytes and treatment with an FGFreceptor blocker attenuated $\mathrm{LVH}$. According to our data, FGF-23 correlated with LVMI, however this relation did not prove independent in multiple regression analysis. In contrast, we noted an independent inverse correlation of PTH levels with LVEF. Association of PTH with myocardial hypertrophy, fibrosis and higher coronary lesion score was described in animal model [33].

LV diastolic dysfunction has been observed already in CKD 1-2 stages [15,33]. CKD severity was the most independent predictor of elevated LV filling pressure [34,35]. Our baseline data in CKD 2-4 show normal diastolic function in $25.8 \%$ in of patients, impaired relaxation in $43.5 \%$, and pseudonormal pattern in $30.6 \%$ of subjects (Table 2).

We noted a positive correlation of EN-RAGE with left atrial diameter and an inverse correlation with E/A. The RAGE pathway could be a causal risk factor for $\mathrm{LVH}$ and coronary atherosclerosis. Recent data show that ENRAGE (also called S100A12) contributes to inflammation and atherosclerosis [36] and an early blockade of RAGE by statins may prevent inflammation in atherosclerosis [37]. S100A12 levels have not been reported to be elevated in CKD patients, but they have been shown to be positively correlated with CRP and negatively correlated with sRAGE [28]. An inverse relationship has been described between sRAGE and LVMI in CKD patients $[38,39]$, but in the present study we failed to note such a correlation.

During the follow-up period we noted a rising percentage of subjects with increased LVMI, abnormal LV geometry, decreased LVEF and LV diastolic dysfunction (Table 2), but this trend was not significant, probably due to the time span limited to $36 \pm 10$ months.

Currently, the regression of LVH may be achieved mainly by antihypertensive and anemia treatment $[16,40]$. Of note, 48 week therapy with paricalcitol did not alter LVMI or improve diastolic dysfunction in patients with CKD (PRIMO study) [41]. To specifically target LVH in the CKD population, we need to better understand the molecular events that promote LVH even in the absence of pressure or volume changes in CKD. Randomized controlled trials are needed to find whether LVH, cardiac fibrosis, and electrical instability that plague patients with CKD can be prevented by aggressive multifactorial therapy started early in CKD, possibly including therapeutic lowering of PIGF, FGF23 or EN-RAGE levels. In this prospective observational study we performed repeated laboratory assessment in a close timely relation to echocardiographic measurements, in order to analyse dynamic changes and correlations of these parameters. We must call attention to some limitations of the present study: due to a relatively high number 
of variables and statistical tests performed in a limited number of subjects, we cannot exclude the possibility of false positive findings. However, appropriate multiple regression stepwise analyses (i.e. a multimarker approach) to detect independent correlations of variables, were performed. We did not consider appropriate to perform ROC curves, as this analysis is considered meaningful in at least 100 observations [42]. Another limitation is the assessment of the filling pattern only from transmitral flow. However, normal pattern was distinguished from pseudonormal by experienced cardiologists taking into account also pulmonary venous flow, left atrial dilatation and in some patients also tissue Doppler imaging. We did not systematically perform the mitral annulus excursion velocity measurements using tissue Doppler, since it was not routinely used in 2005, at the beginning of the study.

\section{Conclusions}

Our data describe for the first time an independent and significant relationship of PIGF to increased LV mass in mild to moderate CKD. EN-RAGE seems more likely related to diastolic dysfunction in this population. We report serial echocardiographic changes in CKD 2-4, such as increased LV mass index and diastolic dysfunction progressing with time along with the declining renal function. Further investigation is needed to demonstrate which strategy is most efficient in preserving the cardiac structure and function.

\begin{abstract}
Abbreviations
ACE: Angiotensin-converting-enzyme; AGEs: Advanced glycation Endproducts; ANCA: Anti neutrophile cytoplasma antibodies; ARBs: Angiotensin II receptor; BNP: B-type natriuretic peptide; BSA: Body Surfaře Area; CKD: Chronic kidney disease; CTnl: Cardiac Troponin l; CV: Cardiovascular; DT: Decelaration Time; DTE-MI: Decelaration Time on Mitral Valve; E/A ratio: Ratio between early (E) and late (atrial - A) ventricular filling velocity; ECLIA: Electrochemiluminescence immunoassay; eGFR: Estimated glomerular filtration rate; ELISA: Enzyme-Linked ImmunoSorbent Assay; EN-RAGE: Extracellular newly identified RAGE-binding protein; FGF-23: Fibroblast growth factor 23; IgA: Immunoglobuline A; IVSd: Interventricular Septal Thickness at Diastole; LAD: Left atrial diameter; LV: Left ventricle; LVEDD: Left ventricular end-diastolic diameter; LVEDV: Left ventricular end-diastolic volume; LVEF: Left ventricular ejection fraction; LVESV: Left ventricular end-systolic volume; LVH: Left ventrikle hypertrophy; LVMI: Left ventricular mass index; MDRD: Modification of. Diet in Renal Disease; MMPs: Matrixmetalloproteinases; ms: millisecond; NF-kB: Nuclear factor kappa-light-chain-enhancer of activated B cells; NYHA: New York Heart Association; PAPP-A: Pregnancy associated protein; PIGF: Placental growth factor; PRIMO: study Paricalcitol Capsules Benefits in Renal Failure Induced Cardiac Morbidity in Subjects With Chronic Kidney Disease Stage 3/4; PTH: Parathyroid hormone; PWTd: Diastolic posterior wall thickness; RAGE: Receptor for Advanced glycation Endproducts; ROC: Receiver operating characteristic; RWT: Relative wall thickness; SWTd: Diastolic septal wall thickness; TAG: Triacylglycerols; TNF: Tumour necrosis factor.
\end{abstract}

\section{Competing interests}

All the authors declare that they have no competing interests.

\section{Authors' contribution}

MP participated in sample collection, clinical data collection, laboratory processing and preparation of manuscript. MK is the main consultant, took part in laboratory processing, interpretation of the data and preparation of manuscript. $\mathrm{MH}$ was inestimable in sample collection and clinical data collection. VD, EN, AB and DA are experienced cardiologists who effected echocardiographic measurements, interpretation of the data and manuscript preparation. BM was responsible for statistical analysis. HB participated in biochemical analysis of study samples. TZ, AL and VT provided expert opinion, took important part in data interpretation and manuscript preparation. All authors read and approved the final manuscript.

\section{Acknowledgements}

This study was supported by research projects: RVO-VFN64165/2012 Ministry of Health and the research project of Charles University P25/LF1/2. The authors are thankful to Mgr. Švarcová, Mrs. Hudcová and Miškovská for technical assistance.

\section{Author details}

'Department of Nephrology, First Faculty of Medicine, Charles University, Prague, Czech Republic. ${ }^{2}$ Institute of Medical Biochemistry and Laboratory Medicine, First Faculty of Medicine, Charles University and General University Hospital, Prague, Czech Republic. ${ }^{3}$ 2nd Department of Medicine -

Department of Cardiovascular Medicine First Faculty of Medicine, Charles University and General University Hospital, Prague, Czech Republic. ${ }^{4} \mathrm{Clinical}$ Biochemistry, Haematology and Immunology, Na Homolce Hospital, Prague, Czech Republic.

Received: 31 October 2012 Accepted: 26 June 2013

Published: 11 July 2013

\section{References}

1. Luke RG: Chronic renal failure: a vasculopathic state. N Engl J Med 1998, 339(12):841-843.

2. Pateinakis $P$, Papagianni A: Cardiorenal syndrome type 4-cardiovascular disease in patients with chronic kidney disease: epidemiology, pathogenesis, and management. Int J Nephrol. 2011, 2011:938651.

3. Kalantar-Zadeh K, Shah A, Duong U, Hechter RC, Dukkipati R, Kovesdy CP: Kidney bone disease and mortality in CKD: revisiting the role of vitamin D, calcimimetics, alkaline phosphatase, and minerals. Kidney Int Suppl 2010, 117:S10-S21.

4. Covic A, Voroneanu L, Goldsmith D: The effects of vitamin D therapy on left ventricular structure and function - are these the underlying explanations for improved CKD patient survival? Nephron Clin Pract 2010, 116(3):187-195.

5. Ogunyankin KO: Assessment of left ventricular diastolic function: the power, possibilities, and pitfalls of echocardiographic imaging techniques. Can J Cardiol 2011, 27(3):311-318.

6. Nakamura T, Funayama H, Kubo N, Yasu T, Kawakami M, Momomura S, Ishikawa SE: Elevation of plasma placental growth factor in the patients with ischemic cardiomyopathy. Int J Cardio/ 2009, 131(2):186-191.

7. Torry RJ, Tomanek RJ, Zheng W, Miller SJ, Labarrere CA, Torry DS: Hypoxia increases placental growth factor expression in human myocardium and cultured neonatal rat cardiomyocytes. J Heart Lung Transplant 2009, 28(2):183-190.

8. Pan P, Fu H, Zhang L, Huang H, Luo F, Wu W, Guo Y, Liu X: Angiotensin II upregulates the expression of placental growth factor in human vascular endothelial cells and smooth muscle cells. BMC Cell Biol 2010, 11:36.

9. Fialová L, Kalousová M, Soukupová J, Sulková S, Merta M, Jelínková E, Horejsí M, Srámek P, Malbohan I, Mikulíková L, Tesar V, Zima T: Relationship of pregnancy- associated plasma protein-a to renal function and dialysis modalities. Kidney Blood Press Res 2004, 27(2):88-95.

10. Kim JK, Park S, Lee MJ, Song YR, Han SH, Kim SG, Kang SW, Choi KH, Kim HJ, Yoo TH: Plasma levels of soluble receptor for advanced glycation end products (sRAGE) and proinflammatory ligand for RAGE (EN- RAGE) are associated with carotid atherosclerosis in patients with peritoneal dialysis. Atherosclerosis 2012, 220(1):208-214.

11. Pilz S, Tomaschitz A, Friedl C, Amrein K, Drechsler C, Ritz E, Boehm BO, Grammer TB, März W: Vitamin D status and mortality in chronic kidney disease. Nephrol Dial Transplant 2011, 58(3):374-382.

12. Isakova $T$, Xie H, Yang W, Xie D, Anderson AH, Scialla J, Wahl P, Gutiérrez OM, Steigerwalt S, He J, Schwartz S, Lo J, Ojo A, Sondheimer J, Hsu CY, Lash J, Leonard M, Kusek JW, Feldman HI, Wolf M, Chronic Renal Insufficiency Cohort (CRIC) Study Group: Fibroblast growth factor 23 and risks of 
mortality and end-stage renal disease in patients with chronic kidney disease. JAMA 2011, 305(23):2432-2439.

13. Lang RM, Bierig M, Devereux RB, Flachskampf FA, Foster E, Pellikka PA, Picard MH, Roman MJ, Seward J, Shanewise JS, Solomon SD, Spencer KT, Sutton MS, Stewart WJ, Chamber Quantification Writing Group, American Society of Echocardiography's Guidelines and Standards Committee, European Association of Echocardiography: Recommendations for chamber quantification: a report from the American society of Echocardiography's guidelines and standards committee and the chamber quantification writing group, developed in conjunction with the European association of echocardiography, a branch of the European society of cardiology. J Am Soc Echocardiogr 2005, 18(12):1440-1463.

14. Chao TF, Wang KL, Chuang CF, Chen SA, Yu WC: Atrium electromechanical interval in left ventricular diastolic dysfunction. Eur J Clin Invest 2011, 42(2):117-122

15. Nagueh SF, Appleton CP, Gillebert TC, Marino PN, Oh JK, Smiseth OA, Waggoner AD, Flachskampf FA, Pellikka PA, Evangelisa A: Recommendations for the evaluation of left ventricular diastolic function by echocardiography. Eur J Echocardiogr 2009, 10(2):165-193.

16. Levin A, Djurdjev O, Thompson C, Barrett B, Ethier J, Carlisle E, Barre P, Magner P, Muirhead N, Tobe S, Tam P, Wadgymar JA, Kappel J, Holland D, Pichette V, Shoker A, Soltys G, Verrelli M, Singer J: Canadian randomized trial of hemoglobin maintenance to prevent or delay left ventricular mass growth in patients with CKD. Am J Kidney Dis 2005, 46(5):799-811.

17. Cioffi G, Tarantini L, Frizzi R, Stefenelli C, Russo TE, Selmi A, Toller C, Furlanello F, de Simone G: Chronic kidney disease elicits excessive increase in left ventricular mass growth in patients at increased risk for cardiovascular events. J Hypertens 2011, 29(3):565-573

18. Paoletti E, Bellino D, Gallina AM, Amidone M, Cassottana P, Cannella G: Is left ventricular hypertrophy a powerful predictor of progression to dialysis in chronic kidney disease? Nephrol Dial Transplant 2011, 26(2):670-677.

19. Soleimani A, Nasiri O, Nikoueinejad H, Yousefzade M, Foroozanfard F, Tabatabaizadeh M, Moraveji SA, Rajali M: Prognostic value of B-type natriuretic peptide for assessment of left ventricular function in patients with chronic kidney disease. Iran J Kidney Dis 2011, 5(4):242-247.

20. Henkel DM, Glockner J, Miller WL: Association of myocardial fibrosis, Btype natriuretic peptide, and cardiac magnetic resonance parameters of remodeling in chronic ischemic cardiomyopathy. Am J Cardiol 2011, 109(3):390-394.

21. Foley RN, Curtis BM, Randell EW, Parfrey PS: Left ventricular hypertrophy in new hemodialysis patients without symptomatic cardiac disease. Clin J Am Soc Nephrol 2010, 5(5):805-813.

22. Thadhani R, Appelbaum E, Chang Y, Pritchett Y, Bhan I, Agarwal R, Zoccali C, Wanner C, Lloyd-Jones D, Cannata J, Thompson T, Audhya P, Andress D, Zhang W, Ye J, Packham D, Singh B, Zehnder D, Manning WJ, Pachika A, Solomon SD: Vitamin D receptor activation and left ventricular hypertrophy in advanced kidney disease. Am J Nephro/ 2011, 33(2):139-149.

23. Accornero F, van Berlo JH, Benard MJ, Lorenz JN, Carmeliet P, Molkentin JD: Placental growth factor regulates cardiac adaptation and hypertrophy through a paracrine mechanism. Circ Res 2011, 109(3):272-280.

24. Roncal C, Buysschaert I, Gerdes N, Georgiadou M, Ovchinnikova O, Fischer C, Stassen JM, Moons L, Collen D, De Bock K, Hansson GK, Carmeliet P: Shortterm delivery of anti-PIGF antibody delays progression of atherosclerotic plaques to vulnerable lesions. Cardiovasc Res 2010, 86(1):29-36.

25. Khurana R, Moons L, Shafi S, Luttun A, Collen D, Martin JF, Carmeliet P, Zachary IC: Placental growth factor promotes atherosclerotic intimal thickening and macrophage accumulation. Circulation 2005, 111(21):2828-2836.

26. Cassidy A: Potential role for plasma placental growth factor in predicting coronary heart disease risk in women. Arterioscler Thromb Vasc Biol 2009, 29(1):134-139.

27. Jaffe IZ, Newfell BG, Aronovitz M, Mohammad NN, McGraw AP, Perreault RE, Carmeliet P, Ehsan A, Mendelsohn ME: Placental growth factor mediates aldosterone-dependent vascular injury in mice. J Clin Invest 2010, 120(11):3891-3900.

28. Zakiyanov O, Kalousová M, Zima T, Tesař V: Placental growth factor in patients with decreased renal function. Ren Fail 2011, 33(3):291-297.

29. McQuarrie EP, Patel RK, Mark PB, Delles C, Connell J, Dargie HJ, Steedman T, Jardine AG: Association between proteinuria and left ventricular mass index: a cardiac MRI study in patients with chronic kidney disease. Nephrol Dial Transplant 2011, 26(3):933-938.
30. Canziani ME, Tomiyama C, Higa A, Draibe SA, Carvalho AB: Fibroblast growth factor 23 in chronic kidney disease: bridging the gap between bone mineral metabolism and left ventricular hypertrophy. Blood Purif 2011, 31(1-3):26-32.

31. Faul C, Amaral AP, Oskouei B, Hu MC, Sloan A, Isakova T, Gutiérrez OM, Aguillon-Prada R, Lincoln J, Hare JM, Mundel P, Morales A, Scialla J, Fischer M, Soliman EZ, Chen J, Go AS, Rosas SE, Nessel L, Townsend RR, Feldman HI, St John Sutton M, Ojo A, Gadegbeku C, Di Marco GS, Reuter S, Kentrup D, Tiemann K, Brand M, Hill JA, Moe OW, Kuro-O M, Kusek JW, Keane MG, Wolf M: FGF23 induces left ventricular hypertrophy. J Clin Invest 2011, 121(11):4393-4408.

32. Patel RK, Jardine AG, Mark PB, Cunningham AF, Steedman T, Powell JR, McQuarrie EP, Stevens KK, Dargie HJ, Jardine AG: Association of left atrial volume with mortality among ESRD patients with left ventricular hypertrophy referred for kidney transplantation. Am J Kidney Dis 2010, 55(6):1088-1096

33. Custódio MR, Koike MK, Neves KR, dos Reis LM, Graciolli FG, Neves CL, Batista DG, Magalhães AO, Hawlitschek P, Oliveira IB, Dominguez WW, Moysés RM, Jorgetti V: Parathyroid hormone and phosphorus overload in uremia: impact on cardiovascular system. Nephrol Dial Transplant 2012, 27(4):1437-1445.

34. Chen SC, Su HM, Hung CC, Chang JM, Liu WC, Tsai JC, Lin MY, Hwang SJ, Chen HC: Echocardiographic parameters are independently associated with increased cardiovascular events in patients with chronic kidney disease. Nephrol Dial Transplant 2012, 27(3):1064-1070.

35. Hung MJ, Yang NI, Wu IW, Cheng CW, Liu PC, Chen SJ, Wu MS, Cherng WJ: Three-dimensional echocardiographic assessment of left ventricular remodeling in predialysis chronic kidney disease patients. J Nephrol 2011, 25(1):96-106.

36. Gawdzik J, Mathew L, Kim G, Puri TS, Hofmann Bowman MA: Vascular remodeling and arterial calcification are directly mediated by $\mathrm{S} 100 \mathrm{~A} 12$ (EN-RAGE) in chronic kidney disease. Am J Nephrol 2011, 33(3):250-259.

37. Mahajan N, Bahl A, Dhawan V: C-reactive protein (CRP) up-regulates expression of receptor for advanced glycation end products (RAGE) and its inflammatory ligand EN-RAGE in THP-1 cells: inhibitory effects of atorvastatin. Int J Cardiol 2010, 142(3):273-278.

38. Leonardis D, Basta G, Mallamaci F, Cutrupi S, Pizzini P, Tripepi R, Tripepi G, De Caterina R, Zoccali C: Circulating soluble receptor for advanced glycation end product (sRAGE) and left ventricular hypertrophy in patients with chronic kidney disease (CKD). Nutr Metab Cardiovasc Dis 2012, 22(9):748-755.

39. Lindsey JB, Cipollone F, Abdullah SM, McGuire DK: Receptor for advanced glycation end-products (RAGE) and soluble RAGE (sRAGE): cardiovascular implications. Diab Vasc Dis Res 2009, 6(1):7-14.

40. Zamboli P, De Nicola L, Minutolo R, Chiodini P, Crivaro M, Tassinario S, Bellizzi V, Conte G: Effect of furosemide on left ventricular mass in nondialysis chronic kidney disease patients: a randomized controlled trial. Nephrol Dial Transplant 2011, 26(5):1575-1583.

41. Thadhani R, Appelbaum E, Pritchett Y, Chang Y, Wenger J, Tamez H, Bhan I, Agarwal R, Zoccali C, Wanner C, Lloyd-Jones D, Cannata J, Thompson BT, Andress D, Zhang W, Packham D, Singh B, Zehnder D, Shah A, Pachika A Manning WJ, Solomon SD: Vitamin D therapy and cardiac structure and function in patients with chronic kidney disease: the PRIMO randomized controlled trial. JAMA 2012, 307(7):674-684.

42. Metz CE: Basic principles of ROC analysis. Semin Nucl Med 1978, 8(4):283-298.

\section{doi:10.1186/1471-2369-14-142}

Cite this article as: Peiskerová et al:: Placental growth factor may predict increased left ventricular mass index in patients with mild to moderate chronic kidney disease - a prospective observational study. BMC Nephrology 2013 14:142. 